\title{
Desempenho agronômico do amendoim BRS 423 OL cultivado sob diferentes densidades de semeadura nas condições de Campo Verde-MT
}

\author{
Submetido - 10 jul. $2020 \quad$ Aprovado - 07 ago. $2020 \quad$ Publicado - 14 out. 2020
}

\begin{abstract}
Daniele Fernandes Campos iD
Discente de Agronomia do IFMT Campus São Vicente - Centro de Referência de Campo Verde, Campo Verde, MT, daniele.fernandes@yahoo.com.
\end{abstract}

\begin{abstract}
Jair Heuert ${ }^{\mathbb{D}}$
Programa de Melhoramento do Amendoim - Embrapa, Santo Antônio de Goiás, GO, jair.heuert@embrapa.br.
\end{abstract}

Janderson Aguiar Rodrigues (D)

Docente do IFMT Campus São Vicente - Centro de Referência de Campo Verde, Campo Verde, MT, janderson_zoo@hotmail.com.

Maxuel Fellipe Nunes Xavier (iD

Discente de Agronomia do IFMT Campus São Vicente - Centro de Referência de Campo Verde, Campo Verde, MT, maxuelfellipe90@gmail.com.

Taís de Moraes Falleiro Suassuna (D)

Programa de Melhoramento do Amendoim - Embrapa, Santo Antônio de Goiás, GO, tais.suassuna@embrapa.br.

\section{RESUMO}

A cultura do amendoim apresenta boa adaptação nas condições de cultivo no estado do Mato Grosso, mas informações para otimizar o manejo cultural, como densidade de plantio, são escassas. Objetivou-se com este trabalho avaliar o desempenho agronômico de amendoim BRS 423 OL cultivado em diferentes densidades de semeadura nas condições de Campo Verde-MT. A semeadura foi realizada manualmente no dia 22 de novembro de 2019. 0 delineamento experimental utilizado foi em blocos casualizados, com quatro repetições. Os tratamentos foram cinco densidades de sementes $m^{-1}: 10,15,20,25$ e 30 sementes $m^{-1}$, com a cultivar BRS $423 \mathrm{OL}$. As parcelas foram compostas por quatro linhas de três metros de comprimento, espaçamento ente linhas de noventa centímetros, intervalo entre parcelas de dois metros e parcela útil de 10,8 $\mathrm{m}^{2}$. A colheita foi realizada no dia 20 de março de 2020, aos 112 dias após a emergência. Foram avaliados massa seca por planta (g), número de vagens por planta, estande final de plantas. $\mathrm{m}^{-1}$, massa de 100 grãos $(\mathrm{g})$ e produtividade de vagens $\left(\mathrm{kg} \mathrm{ha}^{-1}\right)$. As densidades de sementes influenciaram na massa seca por planta, número de vagens por planta, estande final de plantas $m^{-1}$ e massa de 100 grãos, de modo que as menores densidades (10 e 15 sementes $\mathrm{m}^{-1}$ ) produziram quantidades de vagens compatíveis estatisticamente às maiores densidades $\left(20,25\right.$ e 30 sementes $\left.m^{-1}\right)$.

Palavras-chave: Arachis hypogaea L.; População; Produtividade.

Agronomic performance of BRS 423 OL peanuts grown under different sowing densities in Campo Verde-MT conditions

\section{ABSTRACT}

Peanut culture is well adapted to growing conditions in the state of Mato Grosso, but information to optimize cultural management, such as planting density, is scarce. The present 
work aimed to evaluate the agronomic performance of BRS 423 OL peanuts, cultivated in different sowing densities under the conditions of Campo Verde-MT. Sowing was done manually on November 22, 2019. The experimental design used was in randomized blocks, with four replications. The treatments were five seed densities $m^{-1}: 10,15,20,25$ and 30 seeds $m^{-1}$, with the cultivar BRS $423 \mathrm{OL}$. The plots were composed by four lines of three meters in length, spacing between lines of ninety centimeters, interval between plots of two meters and a useful plot of $10.8 \mathrm{~m}^{2}$. The harvest was carried out on March 20, 2020, 112 days after the emergency. Dry mass per plant (g), number of pods per plant, final plant stand. $\mathrm{m}^{-1}$, mass of 100 grains $(\mathrm{g})$ and pod yield ( $\left.\mathrm{kg} \mathrm{ha}^{-1}\right)$ were evaluated. Seed densities influenced dry mass per plant, number of pods per plant, final plant stand. $m^{-1}$ and mass of 100 grains, so that the lowest densities (10 and 15 seeds. $\mathrm{m}^{-1}$ ) produced quantities of pods statistically compatible with the highest densities $\left(20,25\right.$ and 30 seeds $\left.m^{-1}\right)$.

Keywords: Arachis hypogaea L.; Population; Productivity.

\title{
Rendimiento agronómico del maní BRS 423 OL cultivado bajo diferentes densidades de siembra en condiciones de Campo Verde-MT
}

\begin{abstract}
RESUMEN
El cultivo de maní está bien adaptado a las condiciones de cultivo en el estado de Mato Grosso, pero la información para optimizar el manejo cultural, como la densidad de siembra, es escasa. El objetivo de este trabajo fue evaluar el rendimiento agronómico de los cacahuetes BRS 423 OL cultivados en diferentes densidades de siembra bajo las condiciones de Campo Verde-MT. La siembra se realizó manualmente el 22 de noviembre de 2019. El diseño experimental utilizado fue en bloques aleatorizados, con cuatro repeticiones. Los tratamientos fueron cinco densidades de semillas $m^{-1}: 10,15,20,25$ y 30 semillas $m^{-1}$, con el cultivar BRS 423 OL. Las parcelas estaban compuestas por cuatro líneas de tres metros de longitud, espaciadas entre líneas de noventa centímetros, intervalo entre parcelas de dos metros y una parcela útil de 10.8 $m^{2}$. La cosecha se realizó el 20 de marzo de 2020, 112 días después de la emergencia. Se evaluaron el peso seco por planta $(g)$, el número de vainas por planta, el soporte final de la planta $\mathrm{m}^{-1}$, la masa de 100 granos $(\mathrm{g})$ y el rendimiento de la vaina ( $\mathrm{g} \mathrm{ha}^{-1}$ ). Las densidades de semillas influyeron en la masa seca por planta, el número de vainas por planta, la masa final de plantas $\mathrm{m}^{-1}$ y la masa de 100 granos, de modo que las densidades más bajas (10 y 15 semillas $\mathrm{m}^{-1}$ ) produjeron cantidades compatibles de vainas estadísticamente a las densidades más altas $\left(20,25\right.$ y 30 semillas $\left.m^{-1}\right)$.
\end{abstract}

Palabras clave: Arachis hypogaea L.; Población; Productividad.

\section{Introdução}

A cultura do amendoim (Arachis hypogaea L.) tem sido estudada nos últimos anos nas condições climáticas de Campo Verde-MT (SANTIN et al., 2019). Destaca-se a produtividade elevada utilizando a cultivar BRS $423 \mathrm{OL}$ (5.947,9 kg ha-1), com incremento de $67 \%$ sobre a estimativa média nacional para cultivo em primeira safra $\left(3.553,0 \mathrm{~kg} \mathrm{ha}^{-1}\right)$, segundo informações da CONAB (2020).

Esta cultura, que é uma importante fixadora de nitrogênio, pode ser uma alternativa para solos arenosos da região, preteridos por outras culturas 
anuais, podendo ser uma excelente opção de diversificação da produção e de mercados. No entanto, é importante a realização de avaliações complementares de desempenho agronômico e arranjos de semeadura, visando observar a adaptação das cultivares e a possível recomendação técnica para o cultivo do amendoim nesta região.

$\mathrm{Na}$ cultura do amendoim, conforme o aumento da população de plantas, tem-se o incremento na produtividade, porém estes ganhos possuem certo limite de número de plantas por unidade de área e podem variar em função da cultivar e das condições ambientais. A população de plantas influencia em características agronômicas como a massa de 100 grãos e produtividade (MOZINGO; WRIGHT, 1994; NAKAGAWA et al., 1994).

Pesquisas realizadas na área experimental do Instituto Federal de Educação, Ciência e Tecnologia de Mato Grosso - Campus São Vicente, Centro de Referência de Campo Verde, MT, testando diferentes densidades de sementes $\left(10,15,20,25\right.$ e 30 sementes $\left.\mathrm{m}^{-1}\right)$, no espaçamento de $0,45 \mathrm{~m}$ com genótipo rasteiro IAC Caiapó, seguiram modelo quadrático, com as maiores produtividades com a população ótima de 24 sementes $\mathrm{m}^{-1}$, nas safras 2017/18 e 2018/19 (XAVIER et al., 2020).

Objetivou-se com este trabalho avaliar o desempenho agronômico de amendoim BRS 423 OL cultivado em diferentes densidades de semeadura nas condições de Campo Verde-MT.

\section{Material e métodos}

O experimento foi desenvolvido na safra 2019/20, na área experimental do Instituto Federal de Educação, Ciência e Tecnologia de Mato Grosso - Campus São Vicente, Centro de Referência de Campo Verde, localizado no município de Campo Verde - MT, cujas coordenadas geográficas são $55^{\circ} 10^{\prime} 08^{\prime \prime} \mathrm{W}$ e $15^{\circ} 32^{\prime} 48^{\prime \prime} \mathrm{S}$, com altitude de 736 metros. A semeadura foi realizada manualmente no dia 22 de novembro de 2019.

O delineamento experimental utilizado foi em blocos casualizados, com quatro repetições. Os tratamentos constaram de cinco densidades de 
sementes por metro $\left(\mathrm{m}^{-1}\right): 10,15,20,25$ e 30 sementes $\mathrm{m}^{-1}$, com a cultivar BRS $423 \mathrm{OL}$, desenvolvida pelo Programa de Melhoramento do Amendoim da Embrapa. As parcelas foram compostas por quatro linhas de três metros de comprimento, espaçamento ente linhas de noventa centímetros, intervalo entre parcelas de dois metros e área da parcela de 10,8 $\mathrm{m}^{2}$.

O manejo fitossanitário da área experimental seguiu as recomendações para a cultura. O manejo fitossanitário foi realizado com controle de plantas daninhas realizado com seis aplicações de herbicida: glifosato (2,0 kg p.c.ha-1) aplicado no dia 11/10/2019, quizalofope-p-etílico $\left(1,0\right.$ L p.c.ha $\left.^{-1}\right)+$ etoxissulfurom $\left(0,05 \mathrm{~kg} \mathrm{p.c.ha}^{-1}\right)$ no dia 22/10/2019 e

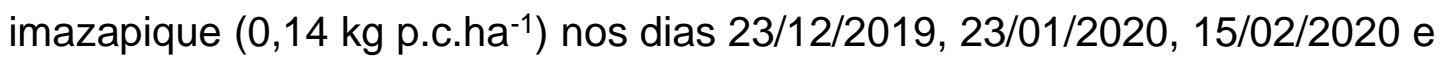
27/02/2020. O manejo de pragas e doenças foi realizado com sete aplicações de inseticida clorfenapir $\left(0,5 \mathrm{~L} \mathrm{p.c.ha-}^{-1}\right)$ e fungicidas clorotalonil $\left(1,5\right.$ L p.c.ha $\left.^{-1}\right)$, pyraclostrobina + epoxiconazol $\left(0,6\right.$ L p.c.ha $\left.^{-1}\right)$ nos dias 23/12/2019, 03/01/2020, 13/01/2020, 23/01/2020, 01/02/2020, 15/02/2020 e $27 / 02 / 2020$.

Com base na necessidade do solo, foi realizado adubação de semeadura de $400 \mathrm{~kg} \mathrm{ha}^{-1}$ de superfosfato simples (SFS) no sulco de plantio. No tratamento de sementes foi utilizado carbendazim, na dose de $0,1 \mathrm{~L}$ por $100 \mathrm{~kg}$ de sementes. Foram feitas duas aplicações de adubação de cobertura, nos dias 03/01/2020 e 13/01/2020, ambas na dose de $50 \mathrm{~kg} \mathrm{ha}^{-1}$ de cloreto de potássio $(\mathrm{KCl})$ e uma aplicação de gesso agrícola no dia 03/01/2020 na dose de $500 \mathrm{~kg} \mathrm{ha}^{-1}$.

A colheita foi realizada no dia 20 de março de 2020, aos 112 dias após a emergência (DAE). Foram avaliados massa seca por planta (g) e número de vagens por planta, por meio da escolha aleatória de 5 plantas das duas linhas centrais. $O$ estande final de plantas $\mathrm{m}^{-1}$, massa de 100 grãos (g) e produtividade de vagens $\left(\mathrm{kg} \mathrm{ha}^{-1}\right)$, foram avaliados mediante contagem de plantas, pesagem de grãos e vagens da área de 3,6 $\mathrm{m}^{2}$ centrais da parcela. Os dados foram submetidos à análise de variância (Teste $F$ ) e as médias dos tratamentos foram comparadas por regressão linear, por meio do programa computacional SISVAR 5.6 (FERREIRA, 2019). 


\section{Resultados e discussão}

Os resultados da análise de variância e os respectivos valores de quadrados médios (tratamento e bloco), médias e coeficiente de variação (C.V.\%) podem ser observados na Tabela 1. Observa-se diferença significativa para as variáveis massa seca por planta (g), número de vagens por planta, estande final de plantas $\mathrm{m}^{-1}$ e massa de 100 grãos (g) em função da densidade de sementes $\mathrm{m}^{-1}$ com a cultivar BRS $423 \mathrm{OL}$ no ano agrícola 2019/20. Verifica-se que não houve diferença significativa apenas para produtividade de vagens $\left(\mathrm{kg} \mathrm{ha}^{-1}\right)$.

Tabela 1. Quadro da análise de variância de massa seca por planta (g), número de vagens por planta, estande final plantas $\mathrm{m}^{-1}$, massa de 100 grãos (g) e produtividade de vagens $\left(\mathrm{kg} \mathrm{ha}^{-1}\right)$ em função de densidades de sementes da cultivar BRS 423 OL. Campo Verde-MT, 2019/20.

\begin{tabular}{|c|c|c|c|c|}
\hline \multirow{2}{*}{ Variáveis } & \multicolumn{2}{|c|}{ Quadrados Médios } & \multirow{2}{*}{ Média } & \multirow{2}{*}{ C.V.\% } \\
\hline & Tratamento & Bloco & & \\
\hline Massa seca por planta (g) & $414,64^{*}$ & $62,96^{*}$ & 35,98 & 8,27 \\
\hline Número de vagens por planta & $124,97^{*}$ & $22,78^{\text {ns }}$ & 30,04 & 10,20 \\
\hline Estande final de plantas $\mathrm{m}^{-1}$ & $99,57^{\star}$ & $0,78^{\text {ns }}$ & 15,29 & 11,43 \\
\hline Massa de 100 grãos (g) & $18,66^{*}$ & $2,97^{\mathrm{ns}}$ & 72,01 & 2,15 \\
\hline Produtividade de vagens $\left(\mathrm{kg} \mathrm{ha}^{-1}\right)$ & $110.455,75^{\mathrm{ns}}$ & $35.108,63^{\text {ns }}$ & $4.624,35$ & 7,09 \\
\hline
\end{tabular}

As variáveis massa seca por planta (g) e número de vagens por planta foram ajustadas seguindo ajuste quadrático negativo (Figuras 1.A e 1.B). De acordo com Xavier et al. (2020), conforme aumenta-se a densidade de sementes $\mathrm{m}^{-1}$ o resultado é inversamente proporcional a massa seca das plantas $(\mathrm{g})$, pois as densidades de 25 e 30 sementes $\mathrm{m}^{-1}$ possuem as menores massas, ou seja, provavelmente as plantas não ramificaram e produziram massa, tanto quanto as submetidas nas densidades de 10, $15 \mathrm{e}$ 20 sementes $\mathrm{m}^{-1}$ que obtiveram as maiores massas.

Quanto ao número de vagens por planta, as densidades de 10 e 15 sementes $\mathrm{m}^{-1}$ apresentam as maiores quantidades de vagens por planta, em relação as densidades de 20, 25 e 30 sementes $\mathrm{m}^{-1}$. Segundo Xavier et al. 
(2020), conforme diminui a densidade de sementes, obtém-se maior número de vagens por planta, possivelmente quando as plantas são submetidas a menores densidades há menor gasto energético utilizado na competição entre elas, com isso, direcionam a energia para a produção de vagens, ou seja, para a formação de frutos.

O estande final de plantas $\mathrm{m}^{-1}$ seguiu modelo quadrático positivo (Figura 1.C), obtendo o estande final máximo de 19,8 plantas $\mathrm{m}^{-1}$ com a densidade de 26,3 sementes $\mathrm{m}^{-1}$. Corroborando com Nakagawa et al. (1994), que observaram que nas maiores densidades (20, 25 e 30 sementes $\mathrm{m}^{-1}$ ), conforme aumentou-se a quantidade de sementes, a percentagem de germinação e sobrevivência de plantas foi reduzida, pois nas menores densidades (10 e 15 sementes $\mathrm{m}^{-1}$ ) os estandes finais colhidos foram mais próximas a quantia semeada, resultado da boa germinação, sobrevivência e menor concorrência entre as plantas pelas necessidades do meio (agua, luz e nutrientes).

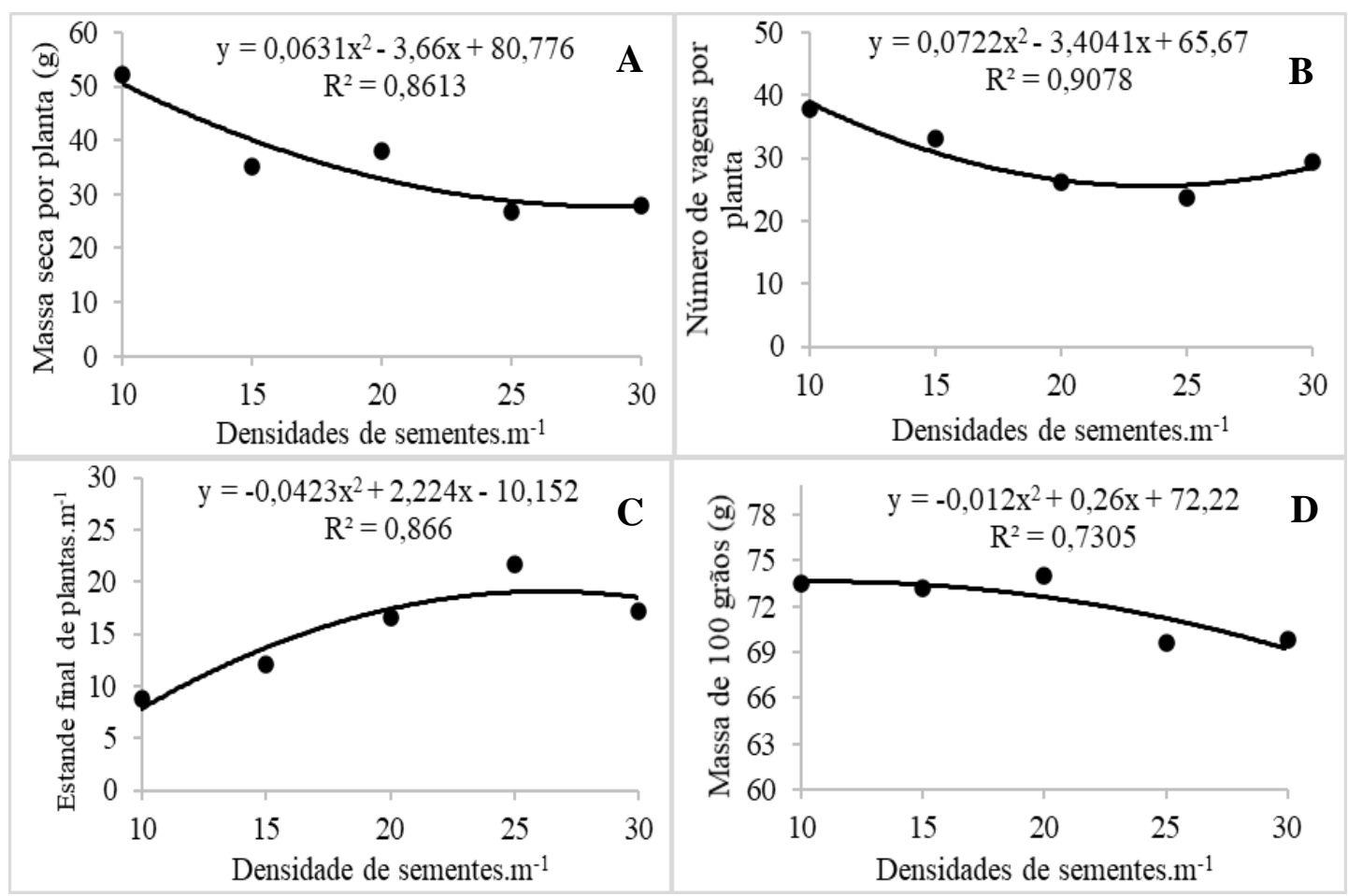

Figura 1. Massa seca por planta (g) (A), número de vagens por planta (B), estande final de plantas. $\mathrm{m}^{-1}$ (C) e massa de 100 grãos (g) (D) em função de densidades de sementes da cultivar BRS 423 OL. Campo Verde-MT, 2019/20. 
A massa de 100 grãos (g) também seguiu ajuste quadrático positivo (Figura 1.D), correlato ao obtido na variável estande final de plantas. $\mathrm{m}^{-1}$. Com base nos ajuste, a massa de 100 grãos máxima é de 73,63 g, obtida com a densidade de 10,83 sementes $\mathrm{m}^{-1}$, sendo provável que conforme menos plantas germinadas e estabelecidas para o crescimento, tem-se menor competição entre elas, logo elas podem utilizar melhor sua reserva e produção energética para formação dos grãos, podendo obter maior granulometria, em relação as demais densidades testadas.

A produtividade de vagens $\left(\mathrm{kg} \mathrm{ha}^{-1}\right)$ não foi influenciada por diferentes densidades de semeadura com produtividade média 4.624,35 kg ha $^{-1}$ (Tabela 1 ), com acréscimo de $30 \%$ quando comparado a média nacional de $3.553 \mathrm{~kg} \mathrm{ha}^{-1}$, estimada pela CONAB (2020).

\section{Conclusões}

As densidades de sementes influenciaram na massa seca por planta, número de vagens por planta, estande final de plantas $\mathrm{m}^{-1}$ e massa de 100 grãos, de modo que as menores densidades (10 e 15 sementes $\mathrm{m}^{-1}$ ) produziram quantidades de vagens compatíveis estatisticamente às maiores densidades $\left(20,25\right.$ e 30 sementes $\left.\mathrm{m}^{-1}\right)$.

\section{Agradecimentos}

Os autores agradecem ao IFMT Campus São Vicente - Centro de Referência de Campo Verde e ao Programa de Melhoramento do Amendoim da Embrapa, localizada em Santo Antônio de Goiás-GO.

\section{Referências}

CONAB. Acompanhamento da Safra Brasileira de grãos. Safra 2019/20 Oitavo levantamento, v. 7, n. 8, p. 1-66, maio 2020. Disponível em: <https://www.conab.gov.br/info-agro/safras>. Acesso em: 13 jun. 2020.

FERREIRA, D. F. SISVAR: a computer analysis system to fixed effects split plot type designs. Revista Brasileira de Biometria, [S.L.], v. 37, n. 4, p. 529, 20 dez. 2019. http://dx.doi.org/10.28951/rbb.v37i4.450

MOZINGO, R. W.; WRIGHT, F. S. Diamond-shaped seeding of six peanut cultivars. Peanut Science, v. 21, n. 1, p. 5-9, 1994. 
NAKAGAWA, J.; LASCA, D. C.; NEVES, J. P. S.; NEVES, G. S.; SANCHEZ, S. V.; BARBOSA, V.; SILVA, M. N.; ROSSETTO, C. A. V. Efeito da densidade de semeadura na produção de amendoim. Pesquisa Agropecuária Brasileira, v. 29, n. 10, p. 1547-1555, 1994.

SANTIN, V.; PEROZINI, A. C.; ARAÚJO, C.; GIRON, F. G.; HEUERT, J.; XAVIER, M. F. N.; SUASSUNA, T. M. F. Desempenho de cultivares de amendoim nas condições de Campo Verde-MT. In: Anais do Encontro Sobre a Cultura do Amendoim, 16., 2019, Jaboticabal. Anais eletrônicos... Campinas: GALOÁ, 2019. Disponível em: $<$ https://proceedings.science/encontro-amendoim-2019/papers/desempenhode-cultivares-de-amendoim-nas-condicoes-de-campo-verde-mtl>. Acesso em: 13 jun. 2020.

XAVIER, M. F. N.; PEROZINI, A. C.; ARAÚJO, C.; GIRON, F. G.; SANTIN, V.; MARTINOTTO, C.; CARMO, E. M. T. Características agronômicas e produtividade de genótipos de amendoim (Arachis hypogaea L.) em diferentes populações. Nucleus, v. 17, n. 1, p. 151-171, 2020. 